\title{
Time-motion analysis and physiological responses of small-sided team handball games in youth male players: Influence of player number
}

\author{
Jan Bělka*, Karel Hůlka, Michal Šafáŕ, Lada Dušková, Radim Weisser, and Václav Riedel \\ Faculty of Physical Culture, Palacký University Olomouc, Olomouc, Czech Republic
}

Copyright: (C) 2016 J. Bělka et al. This is an open access article licensed under the Creative Commons Attribution License (http://creativecommons.org/licenses/by/4.0/).

\begin{abstract}
Background: Effective training depends on knowledge of a sport's requirements. Small-sided games (SSG) are a spontaneous form of specific training, where exercise intensity can be manipulated mainly by modifying external factors. In SSG the players develop technical and tactical skills in the similar situations, such as during a match and can also develop their physical skills. Objective: The purpose of this study was to examine the distance covered and physiological response of altering the number of youth male players during small-sided team handball games with modified rules. Methods: The subjects consisted of 12 male youth team handball players (age $16.6 \pm 0.5$ years) playing the first league for youth male players in the Czech Republic. The study was conducted during six weeks (one training session per week). Only three SSG were played in each training session. The SSG were played, first with five players on each side ( 5 vs. 5), then four ( 4 vs. 4 ), then three ( 3 vs. 3 ). Each game was four minutes long, followed by three minutes of passive rest. Results: The players covered the greatest distance $(520.6 \pm 61.4 \mathrm{~m})$ in the SSG 3 vs. 3 . There was a difference in the distance covered between players in the 3 vs. 3 SSG and the other SSG (4 vs. 4 and 5 vs. 5 ) $(p=.041$ and $p=.043$, respectively). In individual speed zones a difference occurred only in the first and third speed zone and always among the 3 vs. 3 and 5 vs. 5 SSG $(p=.034$ and $p=.044)$, respectively. The highest average intensity $\left(87.9 \pm 4.8 \% \mathrm{HR}_{\max }\right)$ was in 3 vs. $3 \mathrm{SSG}$. Loading of the players in 5 vs. 5 was lower compared to 4 vs. 4 ( $p=.035$ ) and 3 vs. $3(p<.001)$. There was a difference in zone load intensity (>90\% $\mathrm{HR}_{\max }$ ) between 3 vs. 3 and 5 vs. 5 SSG $(p=.041)$. Conclusions: These results indicate that changing the number of players during SSG with modified rules in youth team handball may be used to manipulate the physiological response during youth team handball training.
\end{abstract}

Keywords: time-motion analysis, heart rate, rating of perceived exertion, sport-specific training, team handball

\section{Introduction}

Team handball is an Olympic sport played throughout the world. Each team handball team consists of sixteen players with only seven players on the playing area (six outfield players and one goalkeeper). Team handball players have to coordinate their movements well in running, jumping, pushing, change of direction and team handball-specific movements, such as passing, catching, throwing, checking and blocking (Michalsik \& Aagaard, 2015; Michalsik, Aagaard, \& Madsen, 2013; Michalsik, Aagaard, \& Madsen, 2015; Michalsik, Madsen, \& Aagaard, 2014; Michalsik, Madsen, \& Aagaard, 2015a, 2015b).

\footnotetext{
* Address for correspondence: Jan Bělka, Department of Sport, Faculty of Physical Culture, Palacký University Olomouc, třída Míru 117, 77111 Olomouc, Czech Republic. E-mail: jan.belka@upol.cz
}

Male team handball players covered a total distance of 3,627 $\pm 568 \mathrm{~m}$ (group means $\pm \mathrm{SD}$ ) per match with a total effective playing time of $53.9 \pm 5.9$ minutes, while full-time ( 60 minutes playing time) male handball players covered $3,945 \pm 538 \mathrm{~m}$. The mean speed was $6.40 \pm 1.01 \mathrm{~km} \cdot \mathrm{h}^{-1}$ (Michalsik et al., 2013; Michalsik \& Aagaard, 2015).

Mean heart rate and relative workload during male match play were $163 \pm 5$ beats $\cdot \mathrm{min}^{-1}$ and $70.9 \pm 6.0 \%$ of $\mathrm{VO}_{2 \max }$, respectively. Post-match blood lactate concentration was $4.8 \pm 1.9 \mathrm{mmol} \cdot \mathrm{L}^{-1}$ (range: 2.8-10.8 $\mathrm{mmol} \cdot \mathrm{L}^{-1}$ ) (Michalsik et al., 2015b). Players showed $36.9 \pm 13.1$ (group mean $\pm \mathrm{SD}$ ) high-intense technical playing actions per match with a mean total effective playing time of $53.9 \pm 5.9$ minutes. In attack, each player performed $6.0 \pm 5.2$ fast breaks, received $34.5 \pm 21.3$ tackles in total, and in defense performed $3.7 \pm 3.5$ blockings, $3.9 \pm 3.0$ claspings, and $5.8 \pm 3.6$ hard tackles (Michalsik et al., 2015a). 
Studies oriented on soccer indicate that, in order to reproduce the physical, technical and tactical requirements of a real match (Reilly \& White, 2004; Sassi, Reilly, \& Impellizzeri, 2004), coaches often use smallsided games (SSG) in their training programmes (Aguiar, Botelho, Lago, Maças, \& Sampaio, 2012). SSG started as an optimal task to optimize training time by fulfilling the broad range of fitness requirements without compromising skill performance and decision-making (Aguiar et al., 2012). They allow more time spent managing the ball within game-like conditions compared to non-specific training (Halouani, Chtourou, Gabbett, Chaouachi, \& Chamari, 2014). Sport-specific conditioning in the form of SSG according to the number of players has been evaluated extensively in team sports such as soccer (Da Silva et al., 2011; Dellal, HillHass, Lago-Penas, \& Chamari, 2011), rugby (Foster, Twist, Lamb, \& Nicholas, 2010; Kennett, Kempton, \& Coutts, 2012), but less so in basketball (Klusemann, Pyne, Foster, \& Drinkwater, 2012; Sampaio, Abrantes, \& Leite, 2009).

According to Halouani et al. (2014) the number of players can influence the training intensity of SSG. Recent studies in soccer have shown that SSG formats with different numbers of players elicit different physiological, perceptual, and time-motion characteristics (Aroso, Rebelo, \& Gomes-Pereira, 2004; Rampinini et al., 2007). So far, there have been only three studies (Abade, Abrantes, Ibánez, \& Sampaio, 2014; Buchheit et al., 2009; Corvino, Tessitore, Minganti, \& Sibila, 2014) in team handball dealing with the analysis of internal and external loading in SSG players.

Several factors (e.g. field size, number of players on the field, coach intervention, modification of rules) influence the physiological and technical demands of SSG and thus the desired conditioning stimulus in the training in sport's games (Hill-Haas, Dawson, Impellizzeri, \& Coutts, 2011).

The main aim of our study is to investigate the effect of reducing the number of players on the court in SSG on players' internal (heart rate [HR], zones of load intensity) and external loading (distance covered, speed of movements). External loading can be divided into acyclic (e.g. passing the ball, various kinds of shots, passes) and cyclic activities (e.g. running, walking, jogging) (Šibila, Vuleta, \& Pori, 2004). The results can help team handball coaches of youth players to optimize the training process by selecting SSGs according to their best interest.

\section{Methods}

\section{Participants}

The research group consisted of 12 male team handball field players (age 16.6 \pm 0.5 years) playing in the second league for the youth male players in the Czech Republic. Their height was $179.1 \pm 8 \mathrm{~cm}$, weight $70.4 \pm 10 \mathrm{~kg}$, maximal heart rate $204.3 \pm 2.2$ beats $\cdot \mathrm{min}^{-1}$. Goalkeepers were not involved in this study because their position's requirements differed from the roles of the other players.

All of the procedures were approved by the Ethics Committee of the Faculty of Physical Culture, Palacký University Olomouc.

\section{Procedure}

Measurements were taken in a sports hall on high-quality indoor courts with wooden block floors. The procedure was held every Tuesday 5.00-6.30 p.m. during six weeks (six training sessions). All SSG were played on a court of standard size $(40 \times 20 \mathrm{~m})$. Every training session began with a 15 min warm-up (light jogging, stretching and ball passes). Only three SSG were played in each training session. In the first to third training session only six players played all SSG (the other players, who did not play SSG, practised core training). All players performed the same core training. In the fourth to sixth training sessions the other six players played all the SSG. Only those players who had played in all three SSG per training session were analysed. All 12 players were analysed. Each team had a goalkeeper in the SSG. Next the SSG were played with the number of players being reduced successively from 5 vs. 5 , 4 vs. 4 , to 3 vs. 3 with the goalkeeper, each game lasting 4 min with a 3 min break, as carried out in studies of basketball and soccer (Rampinini et al., 2007; Dellal et al., 2011).

The games were played according to a modified version of the team handball rules (no 2 min suspension and penalties) in order to increase continuity in the game. The disqualification foul was replaced by a free throw. The seven-metre shootings (penalties) were replaced by a free throw. The fixed zone defence in the SSG was 5:0, 4:0, 3:0, respectively. The monitored team used the same defence system in the SSG that they used in their matches. Each game was managed by a coach.

Overall rating of perceived exertion (RPE) was recorded immediately after each SSG using the RPE 6-20 scale (Borg, 1970). Standardized instructions for RPE were given (Borg, 1998), but subjects were asked to refer their RPE to the exercise just completed rather than their perceived exertion at the time of rating. The players recorded their performance always $1 \mathrm{~min}$ after completion of exercise on a prepared RPE sheet. 


\section{Heart rate}

The players' heart rates were monitored during all the SSG in regular 5 second intervals using TEAM Polar ${ }^{2}$ Pro sport testers (Polar Electro Oy, Kempele, Finland). Heart rate was monitored during live playing time (i.e. the complete time that the players were on the court). The maximal HR values were measured by means of the Yo-Yo Intermittent Recovery Test Level 1 (YYIRT1) recovery test (Bangsbo, Iaia, \& Krustrup, 2008) and were established for each player individually (Krustrup et al., 2003). The measurements were performed in a sports hall on a regular team handball court. The zones of load intensity were divided into intervals according to Gore (2000) and Hill-Haas, Dawson, Coutts, and Rowsell (2009): Zone 1 (<75\% $\left.\mathrm{HR}_{\max }\right)$, Zone $2\left(75-84 \% \mathrm{HR}_{\max }\right)$, Zone $3(85-90 \%$ $\mathrm{HR}_{\max }$ ), and Zone 4 (> 90\% $\left.\mathrm{HR}_{\max }\right)$.

We computed the average time covered in each zone for each SSG as well as the $\mathrm{HR}_{\text {mean }}$ and $\mathrm{HR}_{\text {max }}$ values of each player. These were presented as the percentage of average heart rate $\left(\% \mathrm{HR}_{\max }\right)$.

\section{Time-motion analyses}

Each of the 18 SSG was recorded using two digital camcorders (Panasonic SDR-H80, 640×480 pixels, Panasonic, Kadoma, Japan; Canon HF10, 1920×1080 pixels, Canon, Tokyo, Japan) placed in a static position approximately six metres from the side-line and nine metres above the court; each camera recorded one half of the court. Time-motion analyses of the team handball players were analysed from the video recordings, using the authorized (Hůlka, Cuberek, \& Svoboda, 2014) software package Video Manual Motion Tracker 1.0 (Palacký University Olomouc, Olomouc, Czech Republic).

Based on the recommendations of other authors (Corvino et al., 2014; Šibila et al., 2004), we categorized the players' gross-movements into standing and walking $0-1.4 \mathrm{~m} \cdot \mathrm{s}^{-1}$ (1st speed zone), jogging $1.4-3.4 \mathrm{~m} \cdot \mathrm{s}^{-1}$ (2nd speed zone), high-intensity running $3.4-5.2 \mathrm{~m} \cdot \mathrm{s}^{-1}$ (3rd speed zone) and maximal speed running (sprinting) $>5.2 \mathrm{~m} \cdot \mathrm{s}^{-1}$ (4th speed zone). From the video record we analysed the number of acyclic activities: shots to the goal, dribbling (one and multiple bounce), passes, turnovers, and attacks per team.

\section{Statistical analyses}

Software Statistica (Version 12.0; StatSoft, Tulsa, OK, USA) was used to process the data. Descriptive statistics mean and standard deviation were used to describe participants' performance during the SSG. The average heart rate values measured during the SSGs were compared. To compare gained data a one-way ANOVA and Bonferroni post-hoc test were used. ANOVA preconditions were checked by Lilliefors test for normality and the Levene's test of homogeneity. The statistical significances for all parts of the analysis were determined at $p \leq .05$.

\section{Results}

The greatest total distance covered by SSG players was in the 3 vs. 3 game (Table 1), there was a difference in the 4 vs. 4 SSG $(p=.041)$ and 5 vs. 5 SSG $(p=.002)$ in the total distance covered. In the speed zones differences occurred only in the 1st and 3rd speed zone and always among the 3 vs. 3 and 5 vs. 5 SSG ( $p=.034$ and $p=.044$, respectively) (Table 1). On average, players covered 130.2, 119.5, and $119.1 \mathrm{~m}$ per minute in each SSG (3 vs. 3, 4 vs. 4 and 5 vs. 5), respectively. The RPE was highest in SSG 3 vs. 3 and decreased with the increase in the number of players in SSG (Table 2). The highest average intensity $\left(\% \mathrm{HR}_{\max }\right)$ was in the 3 vs. 3 SSG. Loading of the players in 5 vs. 5 was difference lower compared to 4 vs. $4(p=.035)$ and 3 vs. $3(p<.001)$. Difference in each intensity zone of the load was only in the zone $>90 \% \mathrm{HR}_{\max }$ between 3 vs. 3 and 5 vs. 5 SSG $(p=.041)$. In this intensity zone, the players obtained the longest playing time in 3 vs. 3 and 4 vs. 4 SSG.

Table 3 shows frequency of acyclic activities in each SSG. Reducing the number of the players on the playing area resulted in increased use of the dribbling and reduced number of the passes.

Table 1

Total distance and distances (expressed as $M \pm S D$ ) covered in the four speed zones in each SSG

\begin{tabular}{|c|c|c|c|c|c|}
\hline \multirow[b]{2}{*}{ SSG } & \multirow[b]{2}{*}{ Total distance $(\mathrm{m})$} & \multicolumn{4}{|c|}{ Speed zone $(\mathrm{m})$} \\
\hline & & $1 \mathrm{st}$ & 2 nd & $3 \mathrm{rd}$ & 4 th \\
\hline 5 vs. 5 & $476.4 \pm 52.1$ & $176.6 \pm 38.4^{c}$ & $188.4 \pm 42.1$ & $99.3 \pm 31.6$ & $12.1 \pm 3.7$ \\
\hline 4 vs. 4 & $478.1 \pm 72.7$ & $143.1 \pm 45.9$ & $199.7 \pm 40.4$ & $116.1 \pm 33.2$ & $19.2 \pm 29.2$ \\
\hline 3 vs. 3 & $520.6 \pm 61.4^{\mathrm{a}, \mathrm{b}}$ & $139.7 \pm 39.3$ & $213.2 \pm 39.3$ & $135.2 \pm 29.8^{d}$ & $32.5 \pm 35.9$ \\
\hline
\end{tabular}

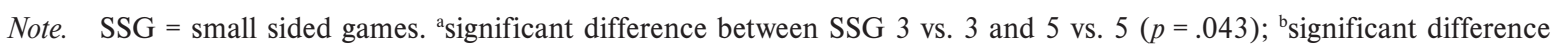

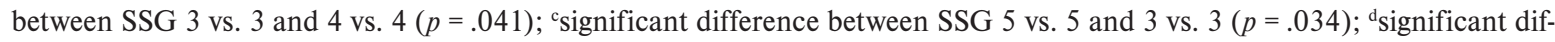
ference between SSG 3 vs. 3 and 5 vs. 5 ( $p=.044)$. Bold face indicates a significant difference. 
Table 2

Rating of perceived exertion's values, heart rate (expressed as $M \pm S D$ ) and time spent in heart rate zones in each SSG

\begin{tabular}{lcccccc}
\hline & & \multicolumn{4}{c}{ Zone of load intensity (\% drill time) } \\
\cline { 4 - 7 } SSG & RPE & \% HR $_{\max }$ & $<75 \% \mathrm{HR}_{\max }$ & $75-84 \% \mathrm{HR}_{\max }$ & $85-90 \% \mathrm{HR}_{\max }$ & $>90 \% \mathrm{HR}_{\max }$ \\
\hline 5 vs. 5 & $12.3 \pm 1.2$ & $80.4 \pm 7.4$ & 4 & 28 & 38 & 30 \\
4 vs. 4 & $14.6 \pm 1.5$ & $\mathbf{8 4 . 6} \pm \mathbf{6 . 3}$ & 1 & 26 & 31 & 42 \\
3 vs. 3 & $17.7 \pm 1.5$ & $\mathbf{8 7 . 9} \pm \mathbf{4 . 8}^{\mathbf{a}}$ & 0 & 21 & 22 & $\mathbf{5 7}^{\mathrm{c}}$ \\
\hline
\end{tabular}

Note. $\quad \mathrm{SSG}=$ small sided games, RPE $=$ Rated Perceived Exertion scale. ${ }^{\text {a }}$ significant difference between SSG 3 vs. 3 and 5 vs. 5

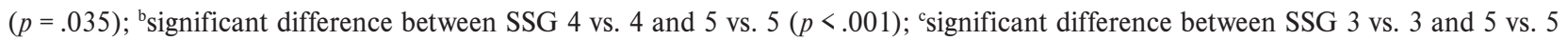
$(p=.041)$. Bold face indicates a significant difference.

Table 3

Frequency of acyclic activities (expressed as $M \pm S D$ ) in each $S S G$

\begin{tabular}{lccccc}
\hline SSG & $\begin{array}{c}\text { Total attacks } \\
\text { per team }\end{array}$ & Shots & Passes & Dribbling & $\begin{array}{c}\text { Technical } \\
\text { mistakes }\end{array}$ \\
\hline 5 vs. 5 & $13.3 \pm 0.9$ & $13.0 \pm 1.5$ & $79.3 \pm 9.1$ & $18.8 \pm 2.4$ & $3.1 \pm 0.9$ \\
4 vs. 4 & $16.2 \pm 2.6$ & $14.3 \pm 2.5$ & $67.2 \pm 7.4$ & $19.2 \pm 4.2$ & $4.7 \pm 1.5$ \\
3 vs. 3 & $17.2 \pm 1.9$ & $17.3 \pm 2.3$ & $66.9 \pm 9.5$ & $21.8 \pm 4.5$ & $2.8 \pm 1.1$ \\
\hline
\end{tabular}

Note. $\quad \mathrm{SSG}=$ small sided games.

\section{Discussion}

In this study, it was shown that the lower the number of players, the longer the distance covered, one reason is that the total playing area was the same in each of the SSG as in the studies by Aroso et al. (2004) and Owen, Twist, and Ford (2004). We cannot compare our results from the male youth players performed during 4 min bouts with modified team handball rules with the nearly or full-time data $(60 \mathrm{~min})$ of elite adult team handball match-play with "normal" rules as this is a different age group of players. Recent studies have shown that SSG formats with different player numbers elicit different physiological, perceptual, and time-motion characteristics (Aroso et al., 2004; Rampinini et al., 2007). Furthermore, changes in game formats and variations in player number appear to have a greater influence on time-motion characteristics than on the physiological responses (Hill-Haas, Coutts, Dawson, \& Rowsell, 2010). Some studies (Owen et al., 2004; Rampinini et al., 2007), show that reducing the number of players and also reducing the playing area may have no effect on the increase in physiologic indicators of players.

The SSG with a reduced number of players seemed to induce higher physiological stimulus, probably due to the larger ratio area per player and the superior number of ball contacts (Abade et al., 2014) and increased the speed movement of players and the intensity of load. According to Abade et al. (2014), available research, mainly in soccer, presents several factors that may contribute to increased intensity in SSG, such as the reduction of the number of players (Capranica, Tessitore, Guidetti, \& Figura, 2001), the greater interaction of the players with the ball and the opponents (Hill-Haas et al., 2009), the increase in individual technical and tactical actions and the higher distance covered with the ball (Katis \& Kellis, 2009). According to our results, we are inclined to agree with the conclusions drawn by Buchheit et al. (2009) and Corvino et al. (2014), that the short duration of the game and reduction in the number of players on the court with SSG leads to an increase in the amount of cyclical movements. Reducing the players on the court will increase their playing activity and intensity load.

In this study, players were in load intensity zones of over $>90 \% \mathrm{HR}_{\max }$ for most of the time in 3 vs. 3 SSG (57\% of the drill time) and this was at its lowest in 5 vs. 5 SSG (30\% of drill time) (Table 2). Similar results $(42 \%$ of the drill time players were in the zone $>90 \% \mathrm{HR}_{\max }$ ) for team handball SSG were found in the study by Corvino et al. (2014), but the playing areas were smaller $(24 \times 12,30 \times 15$ and $32 \times 16 \mathrm{~m})$, playing time was 8 minutes, and players were older. Player motivation is normally considered to be higher when they are using the ball (Helgerud, Engen, Wisloff, \& Hoff, 2001). Our results show that three games promoted high physiological demands, where the players performed the tasks above $80 \%$ of $\mathrm{HR}_{\max }$. Thus, one may argue that these small-sided games can be used for team handball - specific aerobic training with multifactorial training benefits. All these results confirm 
the recommendation made to coaches to use this training method as a specific physical training, also called integrated training. Indeed, sided games produce similar cardiovascular stress to other intermittent exercises specifically designed to improve athletes' endurance (Kelly \& Drust, 2008). In this study RPE was assessed during ball drills with the aim of evaluating the subjective psychophysiological strain (feelings of effort, strain, discomfort, and/or fatigue during both aerobic and resistance training) experienced by team handball players. For each coach, it is important to receive feedback about the players' subjective perception of effort during the training process. Ratings of perceived exertion appear to be a good indicator of the overall intensity of the activity when compared with heart rate and lactate concentration in SSG (Coutts, Rampinini, Marcora, Castagna, \& Impellizzeri, 2009). In general, these studies have shown that SSG formats in soccer and basketball with fewer players elicit greater RPE than the larger formats (Abade et al., 2014; Aroso et al., 2004; Hill-Haas et al., 2009; Impellizzeri et al., 2006; Klusemann et al., 2012; Rampinini et al., 2007). Our results confirm the findings of other studies in soccer (Casamichana \& Castellano, 2010; Rampinini et al., 2007) and team handball (Corvino et al., 2014), namely that with the increase of average heart rate, there will also be increased RPE.

In interpreting the present study, we have to consider a wide variety of factors that influence internal and external intensity. Among these, for example, are nutrition, hyperthermia, dehydration (this could have an effect on overall and local fatigue on the base energy coverage), day to day HR variations, as well as many psychological factors, such as motivation, effort, and angst. Modified rules had an effect on the higher continuity of the game, which could affect the total load (HR and covered distance). To provide a more accurate determination of the load and fatigue in the study, a determination of blood lactate in players would be useful for further research to follow.

\section{Conclusions}

The results show that reducing the number of the players on the field during the handball SSG has an impact on both the internal and external loads of the players. The highest difference was recorded for the total covered distance between SSG 5 vs. 5 and 3 vs. 3 .

The intensity speed of the movements increased after reducing of the players on the playing area. Players spent more time in the gradual attack during SSG 5 vs. 5 than other SSG, in which were rather higher number of the fast break and the total number of attacks. It was reflected in the differences in the heart rate, in which there was a difference between the SSG. Reducing the number of the players on the playing area resulted in increased use of the dribbling and reduced number of the passes. All SSG were intermittent character of the load, as in match of team handball. The findings of the study may be useful in the planning and implementation of training youth team handball players. SSG with reduction of players are suitable for use in training to develop fitness parameters and specific team handball drills. Decreases of the number of youth team handball players in game may allow greater self-recreation of players and greater intervention in game. We would recommend that in a training session SSG of 4 vs. 4 are played rather than 3 vs. 3, because this involves more players in the game who will solve more complicated game situations and players' loads are not so different.

\section{Conflict of interest}

There were no conflicts of interest.

\section{References}

Abade, E., Abrantes, C., Ibánez, S., \& Sampaio, J. (2014). Acute effects of strength training in the physiological and perceptual response in handball small-sided games. Science \& Sports, 29, e83-e89.

Aguiar, M., Botelho, G., Lago, C., Maças, V., \& Sampaio, J. (2012). A review on the effects of soccer small-sided games. Journal of Human Kinetics, 33, 103-113.

Aroso, J., Rebelo, A. N., \& Gomes-Pereira, J. (2004). Physiological impact of selected game-related exercises. Journal of Sports Sciences, 22, 522-531.

Bangsbo, J., Iaia, M., \& Krustrup, P. (2008). The yo-yo intermittent recovery test. A useful tool for evaluation of physical performance in intermittent sports. Sports Medicine, 38, 37-51.

Borg, G. (1970). Perceived exertion as an indicator of somatic stress. Scandinavian Journal of Rehabilitation Medicine, 2, 92-98.

Borg, G. (1998). Borg's perceived exertion and pain scales. Champaign, IL: Human Kinetics.

Buchheit, M., Lepretre, P. M., Behaegel, A. L., Millet, G. P., Cuvelier, G., \& Ahmaidi, S. (2009). Cardiorespiratory responses during running and sport-specific exercises in handball players. Journal of Science and Medicine in Sport, 12, 399-405.

Capranica, L., Tessitore, A., Guidetti, L., \& Figura, F. (2001). Heart rate and match analysis in pre-pubescent soccer players. Journal of Sports Sciences, 19, 379-384.

Casamichana, D., \& Castellano, J. (2010). Time-motion, heart rate, perceptual and motor behaviour demands in small-sides soccer games: Effects of pitch size. Journal of Sports Sciences, 28, 1615-1623. 
Corvino, M., Tessitore, A., Minganti, C., \& Sibila, M. (2014). Effect of court dimensions on players' external and internal load during small-sided handball games. Journal of Sports Science and Medicine, 13, 297-303.

Coutts, A. J., Rampinini, E., Marcora, S. M., Castagna, C., \& Impellizzeri, F. M. (2009). Heart rate and blood lactate correlates of perceived exertion during small-sided soccer games. Journal of Science and Medicine in Sport, 12, 79-84.

Da Silva, C. D, Impellizzeri, F. M., Natali, A. J., De Lima, J. R. P., Bara- Filho, M. G., Silami-Garcxia, E., \& Marins, J. C. B. (2011). Exercise intensity and technical demands of small-sided games in young Brazilian soccer players: Effect of number of players, maturation, and reliability. Journal of Strength and Conditioning Research, 25, 2746-2751.

Dellal, A., Hill-Hass, S., Lago-Penas, C., \& Chamari, K. (2011). SSG in soccer: Amateur vs. professional players' physiological responses, physical, and technical activities. Journal of Strength and Conditioning Research, 25, 2371-2381.

Foster, C. D., Twist, C., Lamb, K. L., \& Nicholas, C. W. (2010). Heart rate responses to small-sided games among elite junior rugby league players. Journal of Strength and Conditioning Research, 24, 906-911.

Gore, C. J. (2000). Physiological tests for elite athletes. Champaign, IL: Human Kinetics.

Halouani, J., Chtourou, H., Gabbett, T., Chaouachi, A., \& Chamari, K. (2014). Small-sided games in team sports training: A brief review. Journal of Strength and Conditioning Research, 28, 3594-3618.

Helgerud, J., Engen, L. C., Wisloff, U., \& Hoff, J. (2001). Aerobic endurance training improves soccer performance. Medicine \& Science in Sports \& Exercise, 33, 1925-1931.

Hill-Haas, S. V., Coutts, A. J., Dawson, B. T., \& Rowsell, G. J. (2010). Time motion characteristics and physiological responses of small sided games in elite youth players: The influence of player number and rule changes. Journal of Strength and Conditioning Research, 24, 2149-2156.

Hill-Haas, S. V., Dawson, B. T., Coutts, A. J., \& Rowsell, G. J. (2009). Physiological responses and time-motion characteristics of various small-sided soccer games in youth players. Journal of Sports Sciences, 27, 1-8.

Hill-Haas, S. V., Dawson, B., Impellizzeri, F. M., \& Coutts, A. J. (2011). Physiology of small-sided games training in football: A systematic review. Sports Medicine, 41, 199-220.

Hůlka, K., Cuberek, R., \& Svoboda, Z. (2014). Time-motion analysis of basketball players: A reliability assessment of Video Manual Motion Tracker 1.0 software. Journal of Sports Sciences, 32, 53-59.

Impellizzeri, F. M., Marcora, S. M., Castagna, C., Reilly, T., Sassi, A., Iaia, F. M., \& Rampinini, E. (2006). Physiological and performance effects of generic versus specific aerobic training in soccer players. International Journal of Sports Medicine, 27, 483-492.

Katis, A., \& Kellis, E. (2009). Effects of small-sided games on physical conditioning and performance in young soccer players. Journal of Sports Science and Medicine, 8, 374-380.

Kelly, D., \& Drust, B. (2008). The effect of pitch dimensions on heart rate responses and technical demands of smallsided soccer games in elite players. Journal of Sports Science and Medicine, 12, 475-479.
Kennett, D. C., Kempton, T., \& Coutts, J. A. (2012). Factors affecting exercise intensity in rugby - specific small-sided games. Journal of Strength and Conditioning Research, 26, 2037-2042.

Klusemann, M. J., Pyne, D. B., Foster, C., \& Drinkwater, E. J. (2012). Optimising technical skills and physical loading in small-sided basketball games. Journal of Sports Sciences, 30, 1463-1471.

Krustrup, P., Mohr, M., Amstrup, T., Rysgaard, T., Johansen, J., Steeensberg, A., ... Bangsbo, J. (2003). The yo-yo intermittent recovery test: Physiological response, reliability, and validity. Medicine \& Science in Sports \& Exercise, 35, 697-705.

Michalsik, L. B., \& Aagaard, P. (2015). Physical demands in elite team handball: Comparisons between male and female players. Journal of Sports Medicine and Physical Fitness, 55, 878-891.

Michalsik, L. B., Aagaard, P., \& Madsen, K. (2013). Locomotion characteristics and match-induced impairments in physical performance in male elite team handball players. International Journal of Sports Medicine, 34, 590-599.

Michalsik, L. B., Aagaard, P., \& Madsen, K. (2015). Technical activity profile and influence of body anthropometry on playing performance in female elite team handball. Journal of Strength and Conditioning Research, 29, 1126-1138.

Michalsik, L. B., Madsen, K., \& Aagaard, P. (2014). Match performance and physiological capacity of female elite team handball players. International Journal of Sports Medicine, 35, 595-607.

Michalsik, L. B., Madsen, K., \& Aagaard, P. (2015a). Technical match characteristics and influence of body anthropometry on playing performance in male elite team handball. Journal of Strength and Conditioning Research, 29, 416-428.

Michalsik, L. B., Madsen, K., \& Aagaard, P. (2015b). Physiological capacity and physical testing in male elite team handball. Journal of Sports Medicine and Physical Fitness, $55,415-429$.

Owen, A. L., Twist, C., \& Ford, P. (2004). Small-sided games: The physiological and technical effect of altering pitch size and player numbers. Insight, 7, 50-53.

Rampinini, E., Impellizzeri, F. M., Castagna, C., Abt, G., Chamari, K., Sassi, A., \& Marcora, S. M. (2007). Factors influencing physiological responses to small-sided soccer games. Journal of Sports Sciences, 25, 659-666.

Reilly, T., \& White, C. (2004). Small-sided games as an alternative to interval-training for soccer players. Journal of Sports Sciences, 22, 559-571.

Sampaio, J., Abrantes, C., \& Leite, N. (2009). Power, heart rate and perceived exertion responses to $3 \times 3$ and $4 \times 4$ basketball small-sided games. Revista de Psicología del Deporte, 18, 463-467.

Sassi, R., Reilly, T., \& Impellizzeri, F. A. (2004). Comparison of small sided games and interval training in elite professional soccer players. Journal of Sports Sciences, 22, 562.

Šibila, M., Vuleta, D., \& Pori, P. (2004). Position-related differences in volume and intensity of large-scale cyclic movements of male players in handball. Kinesiology, 36, 58-68. 